\title{
Current Status and Future Prospects for the Neurosurgical Management of Acute Spinal Cord Injuries
}

\author{
Charles H. Tator, M.D., Ph.D., F.R.C.S.(C)., R. Dean Linden, Ph.D., \\ and Michael G. Fehlings, M.D. \\ Acute Spinal Cord Injury Treatment, Research and Prevention Centre, Toronto \\ Western Hospital, University of Toronto, Toronto, Ontario, Canada
}

There have been great advances in the neurosurgical management of patients with acute spinal cord injury, and the prospects for additional major gains are favourable. This paper will emphasise current practice and future possibilities with respect to the neurosurgical diagnosis and treatment of acute spinal cord injury.

\section{Neurosurgical diagnosis of acute cord injury}

\section{Research programmes}

There is intensive research aimed at improving our ability to make a precise diagnosis of the anatomical, pathological and physiological state of the injured spinal cord. Magnetic resonance (MR) imaging has the capability of demonstrating the anatomical extent and severity of the pathological changes in the cord, including oedema, haemorrhage and necrosis. Hackney et al. (1986) have recently shown that $\mathrm{MR}$ is capable of outlining at least some of these processes in the rat cord after clip compression injury. In our laboratory, we have recently been able to obtain images of the rat cord with a 2.0 Tesla MR system. In addition, it is very likely that $M R$ spectroscopy will be useful for assessing ischaemia and viability of the injured cord.

Great progress has been made with the use of evoked potentials for monitoring the physiological integrity of the spinal cord. For example, somatosensory evoked potentials (SSEP) have been compared with motor evoked potentials (MEP) for assessing the degree of injury to the cord, and Levy et al. (1986) have found that MEPs are more sensitive than SSEPs, a finding that we have confirmed in our laboratory with the clip compression model in the rat. It is likely that the combination of SSEPs and MEPs will accurately assess the physiological state of the motor and sensory tracts of the injured cord, and provide valuable information about the severity of cord injuries and the response to treatment. Figure 1 illustrates SSEPs and MEPs recorded intra-operatively. 


\section{ELECTROPHYSIOLOGICAL MONITORING}

\section{S SEPS}

MEPs
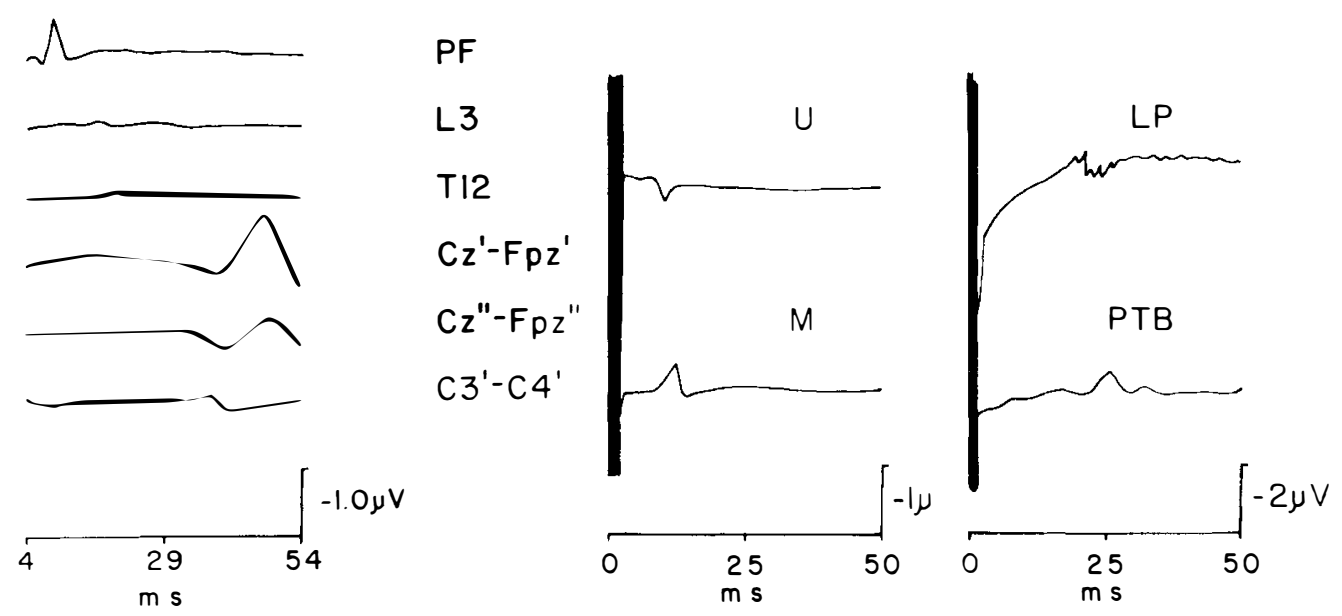

Figure 1 Electrophysiological monitoring of the spinal cord. The tracings on the left of the figure demonstrate somatosensory evoked potentials (SSEP) recorded in response to stimulation of the posterior tibial nerve at the ankle. Recordings were made from the skin overlying the popliteal fossa (PF), the third lumbar vertebra (L3) and the twelfth thoracic vertebra. The responses recorded over the spinal cord are called spinal evoked potentials. Scalp recorded potentials were recorded with three montages: $\mathrm{Cz}^{\prime}-\mathrm{Fpz}^{\prime} ; \mathrm{Cz}^{\prime \prime}-\mathrm{Fpz}^{\prime \prime}$ and $\mathrm{C}^{\prime}-\mathrm{C}^{\prime}$. A 4 ms delay was used to record the SSEPs. The tracings on the right of the figure demonstrate motor evoked potentials (MEP) recorded in response to stimulation of the motor cortex. The responses were recorded with electrodes placed over the ulnar nerve at the elbow $(\mathrm{U})$, the median nerve at the wrist $(\mathbf{M})$, the lateral peroneal nerve at the knee (LP) and the posterior tibial nerve at the ankle (PTB).

Recording both motor and somatosensory evoked potentials is a powerful neurophysiological tool wherein both the motor and sensory function of the spinal cord may be monitored.

\section{Clinical practice}

For the neurosurgeon, computerised tomography (CT) has already had a profound effect on the diagnosis of spinal cord injury. The ability of CT to delineate displacement of bone and disc fragments has been of tremendous importance in neurosurgery. The improved precision of detection of intracanalicular bone fragments with CT has been extremely helpful in demonstrating persisting cord compression (Brant-Zawadzki and Donovan Post, 1983). The indications for myelography have diminished markedly as CT has become more widely used in the acute phase. Indeed, in our Unit, every patient with a spinal injury or a spinal cord injury is examined with CT. As noted above, MR promises to be extremely useful for delineating the effects of trauma on the cord itself, although CT may still be required in many cases to anatomically define the spine-spinal cord relationships (Modic et al., 1984; Paushter et al., 1985).

Evoked potentials have not yet been of proven value for the clinical diagnosis 
of cord injury, mainly due to the limitations of SSEPs. However, the combination of SSEPs and MEPs promises to markedly improve the precision of the neurophysiological diagnosis of cord injury. The use of MEPs for intraoperative monitoring during spinal surgery has only recently been reported (Boyd et al., 1986). Magnetic stimulation of the brain promises to be much more useful than electrical stimulation for eliciting the MEP, although it has not been shown that intra-operative use is feasible. Standardised methods of clinical assessment of spinal cord injuries such as the Frankel system have become more widely accepted by neurosurgeons. This has increased precision of assessing and following the progress of individual patients, and of comparing results from different centres (Tator et al., 1982).

\section{Neurosurgical treatment of acute cord injury}

\section{Research programmes}

Increased knowledge of the pathophysiology of acute spinal cord injury including post-traumatic ischaemia has generated several possible therapeutic strategies. It has been shown that post-traumatic spinal cord blood flow can be restored by counteracting post-traumatic hypotension with volume replacement (Wallace and Tator, 1985) or by improving the microcirculation with calcium channel blockers (Guha et al., 1985). Early decompression of the spinal cord has been proven to be beneficial in experimental cord injury (Dolan et al., 1980) although clinical confirmation is still lacking.

Research on central axonal regeneration is gaining momentum with encouraging results from direct current application, (Wallace and Tator, 1984), foetal brain grafts, and peripheral nerve grafts.

\section{Clinical practice}

Bracken et al. (1985) reported the first randomised, double-blind, prospective, therapeutic trial in a spinal cord injured population, and found that high dose steroids were not superior to low dose steroids. Unfortunately, there was no placebo arm to the study, a flaw recognised by the authors who have included a placebo group in their current study of naloxone and steroids.

There has been a definite trend in many neurosurgical centres for early identification of persisting cord compression and early decompression of the cord in those with significant intracanalicular space occupying lesions, not only in patients with neurological deterioration, but also in those with a 'plateau' in neurological status (Tator et al., 1984). There has also been a trend toward increased utilisation of internal and external fixation devices aimed towards earlier mobilisation of patients. Halo devices have been an outstanding success in allowing safe, early mobilisation of patients thereby reducing the morbidity of prolonged bedrest (Tator et al., 1982). Unfortunately, the effectiveness of many therapeutic measures in the clinical management of spinal cord injury remain unproven, mainly because of the great difficulty in performing prospective, randomised trials in patients with spinal cord injuries. 


\section{Conclusions}

During the past 5 years, there have been considerable gains in the neurosurgical management of acute spinal cord injury. Diagnoses can now be made with much greater precision, and the results of treatment can be assessed more critically. Continuing research promises to add significantly to the neurosurgical management of acute spinal cord injury.

\section{References}

Boyd SG, Rothwell JC, Cowan JMA, et al. 1986 A method of monitoring function in corticospinal pathways during scoliosis surgery with a note on motor conduction velocities. Fournal of Neurology, Neurosurgery and Psychiatry 49:251-257

Bracken MB, Shepart MJ, Hellenbrand KG, et al. 1985 Methylprednisolone and neurological function 1 year after spinal cord injury. Results of the national acute spinal cord injury study. Fournal of Neurosurgery 63:704-713

Brant-Zawadzki M, Donovan Post MJ 1983 Trauma, Chapter 8, pp 149-186 In: Modern Neuroradiology. Vol. 1. Computed tomography of the spine and spinal cord, (Eds) TH Newton and DG Potts. Clavadel Press, San Anselmo

Dolan EJ, Tator CH, ENDRENyi L 1980 The value of decompression for acute experimental spinal cord compression injury. Fournal of Neurosurgery 53:749-755

Guha A, TAtor CH, PIPER I 1985 Increase in rat spinal cord blood flow with the calcium channel blocker, nimodipine. Fournal of Neurosurgery 63:250-259

HACKNEY DB, Asato R, Joseph PM, et al. 1986 Hemorrhage and edema in acute spinal cord compression: Demonstration by MR imaging. Radiology 2: 161:387-390

LEVY W, MCCAFFrey M, YORK D 1986 Motor evoked potential in cats with acute spinal cord injury. Neurosurgery 19:9-19

Modic MT, HARDY RW Jr, WeINSTEIN MA, et al. 1984 Nuclear magnetic resonance of the spine: Clinical potential and limitation. Neurosurgery 15:583-592

PAUShTER DM, Modic MT, MASARYK TJ 1985 Magnetic resonance imaging of the spine: Applications and limitations. Radiologic Clinics of North America 23:551-562

TATOR CH, Ekong CEU, Rowed DW, et al. 1982 Halo devices for the treatment of acute cervical cord injuries. In: Early Management of Acute Spinal Cord Injury. (Ed) CH Tator. Raven Press, New York, Chapter 19, pp 231-256

Tator CH, Rowed DW, Schwartz ML 1982 Sunnybrook cord injury scales for assessing neurological injury and neurological recovery. In: Early Management of Acute Spinal Cord Injury. (Ed) CH Tator. Raven Press, New York, Chapter 2, pp 7-24

TAtor CH, Rowed DW, SCHWARTz ML, et al. 1984 Management of acute spinal cord injuries. Canadian fournal of Surgery 27:289-294

WALlACE MC, TATOR CH 1985 Successful improvement of blood pressure, cardiac output, and spinal cord blood flow following experimental spinal cord injury. Surgical Forum 36: 502-504

Wallace MC, Tator CH, PIPER I 1984 The effect of epidural direct current stimulation on recovery following spinal cord injury. Canadian fournal of Neurological Sciences 11: 331 